\title{
The long journey into the end of the artificial night
}

Sargun A. Tont, staff research associate at Scripps Institution of Oceanography, University of California at San Diego, offers a view on the study of solar eclipses

Although the occurrence of a solar eclipse is one of the most precisely predicted phenomena in the entire solar system, the chances of its coinciding with clear skies are about as good as $\mathrm{Mr}$ Buckley's inviting $\mathrm{Mr}$ Vidal for a transatlantic cruise on his yacht, or Bobby Fischer's opening with a queen's pawn.

Although unfriendly weather is an important obstacle for eclipse lovers, it is far away from being the only one. Getting to the path of an eclipse usually turns out to be a problem that itself exercises a good bit of human ingenuity. For the past of a total solar eclipse seldom favours highly populated regions. There is no reason that it should, of course, yet the number of eclipse paths which run toward far-away places almost appears designed to test the limits of human curiosity. Not surprisingly, then, the traditional vehicles for eclipse expeditions have been mules, donkeys, camels, sledges drawn by Alaskan huskies, trains and, of late years, even chartered jets. In 1972, a novelty was added: a huge, luxurious ocean liner, the T.S.S. Olympia, carried 800 eclipse freaks 900 miles out into the cold Atlantic.

The following paragraph from the New York Times of 30 July 1972 explains my presence on that ship of fools, as it appeared to me at the start:

A team from the Scripps Institute [sic] of Oceanography in La Jolla, California, would conduct an eclipse experiment possible only at sea; they would lower a 300-pound echo chamber over the Olympia's bow to determine whether the layer of microscopic ocean animals called plankton rises at night merely because it gets dark or because of an internal biological clock that would not be triggered by the extraordinary, sudden darkness of the eclipse.

In short, an eclipse provides a sort of artificial night for testing this unique hypothesis.

The ships may be more luxurious and larger, but the ageold problem of not being able to avoid undesirable situations seems to remain the same. The problem in my case was 350 freelance writers who were looking for interesting angles, which primarily meant interviewing me, the expedition leader, and my colleague and friend $\mathrm{Dr}$ Gerald Wick. However, as the big day approached, we were pretty much left alone, and I was able to take a closer look at my fellow passengers. They were a most interesting bunch. Astronaut Scott Carpenter, along with several members of New York high society, were there. So were secretaries, nurses, and several professional astronomers.

People have responded to solar eclipses in a variety of ways. One king, Louis of Bavaria, was frightened to death by it. A solar eclipse stopped a battle between the Lydians and the Medes, and, as late as 1948 , the Korean national elections were postponed, again because of an eclipse. American Indians have described eclipse as "the sun being very sick and going to bed"; and India's Indians have interpreted them as the sun being devoured by evil spirits. Our fellow passengers might have lost some of the fear which beset their early ancestors, but definitely not their reverence and enthusiasm. When I asked several of them how it felt to witness an eclipse, the answers were invariably the same: "There is nothing like it". Like what? Few people seemed to know, or were prepared to say. Yet Leif Robinson, the associate editor of $S k y$ and Telescope and a fellow passenger on board the Olympia, probably summed up best what it is about eclipses that forces us to follow them wherever they take us: "Every solar eclipse unfolds in a predictable way, only the details changing. It is the manner in which these subtleties of colour, brightness, and form are blended that gives each eclipse a flavour as distinct as vintage wine". Conrad would have liked that.

It did not take me long to discard my idea that the passengers were on this cruise to have a good time, in addition to watching the eclipse. It was the eclipse and the eclipse alone that they were after, and many, I am sure, would have swum the distance if that were the only transportation possible. Nevertheless, the entrepreneur of the cruise, Phil Siegler, a social scientist from New York, had also insured a full house by offering something called 'Science at Sea'. Courses ranging from astronomy to birdwatching were taught by astronomers, atmospheric scientists, Scott Carpenter and Leif Robinson.

Nor, as it turned out, was our group the only one mixing pleasure with business. Milner Schaefer, the inventor of cloud seeding and a most charming man, was geared to record cosmic rays; and Dr Williams, of Yale University, passed out photocopied notices inviting all interested passengers to share their eclipse-related dreams with him as a part of his research project ${ }^{1}$. However, the most important scientist on board was the meteorologist whose primary function was to guide the ship to the most favourable (that is, cloud-free) location. Outfitted in a Scottish tweed jacket and impeccably shiny shoes, he entered into Ahab-like trances which never failed to command our closest attention, and his least utterance about the weather was speedily relayed to the farthest corner of the vessel.

Then it happened. It wasn't what I expected. What surprised and fascinated me was not the sudden darkness which swooped down on us with the grace of a hammerhead entering a South-Sea lagoon, but the grasshopperesque chatter of cameras, all 799 of them. I suddenly realised that I might be the only one who was watching it-the rest were busy recording it for posterity, be it for a lecture demonstration for an undergraduate astronomy class at Harvard, or for a slide show especially prepared for a maiden aunt and her boyfriend in Galesburg, Missouri. What a pity! Thanks to the camera, most people became the lovers of an illusion of reality, rather than of the reality itself.

It is that time again and the faithful are getting ready to watch, on 12 October, the total solar eclipse which, according to reports, will be best viewed off the coast of central America $\left(13^{\circ} 42^{\prime} \mathrm{N} 123^{\circ} 07^{\prime} \mathrm{W}\right)$. In order to accommodate the large number of applicants, Sitmar Lines is offering two ocean liners, along with such luminaries as Margaret Mead and Isaac Asimov. If you happen to be in the neighbourhood, take a look at it. It is some sight.

As for our experiment ${ }^{2}$, in the finest scientific tradition, the results were rather ambiguous. Even though some of the organisms responded to the eclipse by migrating vertically, some did not. One of the results was totally unexpected: increased bioluminescent activity during totality. One can offer several hypotheses to explain this phenomenon, but I am sure, to the eclipse lover, this was nothing more than the little bugs celebrating the joyous occasion.

'For the various scientific projects conducted during solar eclipses, see Solar Eclipse Bulletin 1-4 (National Science Foundation, Washington, D.C.; 1973).

${ }^{2}$ For the results of our experiment, see Deep-Sea Research 20, $769-771 ; 1973$. 